DOI 10.37882/2223-2982.2021.09-2.02

\title{
ОБЕСПЕЧЕНИЕ ДОСТУПНОСТИ УЧЕБНЫХ МАТЕРИАЛОВ ПО ЯЗЫКУ СПЕЦИАЛЬНОСТИ ДЛЯ ИНОСТРАННЫХ ВОЕННОСЛУЖАЩИХ
}

\section{ENSURING THE AVAILABILITY OF EDUCATIONAL MATERIALS ON THE LANGUAGE OF THE SPECIALTY FOR FOREIGN MILITARY PERSONNEL \\ L. Aseykina \\ L. Kashina}

Summary: The article deals with the problem of ensuring the availability of authentic materials of the textbook on the language of the specialty in the training of foreign military personnel. The methodology of the research is substantiated, the pedagogical conditions for achieving the goal are identified, recommendations for the organization of educational and methodological work are presented. During the experimental test, the necessity of implementing comprehensive measures to achieve the availability of educational materials was proved, which means that cadets have the opportunity to form and increase their communicative competence in the educational and professional sphere.

Keywords: authentic materials, differentiation, specialty language, adaptation, accessibility, foreign military personnel.
$\mathrm{Y}$ спешная эксплуатация отечественной военной техники за рубежом предполагает подготовку компетентных специалистов. В российских вузах военно-профессиональная подготовка иностранных военнослужащих (ИВС) осуществляется на неродном (русском) языке, знание которого определяет их способность к обучению. Коммуникативная компетенция, существенно влияющая на качество профессионального образования ИВС, формируется у них на подготовительном курсе и на основных курсах при изучении, главным образом, дисциплины «Язык специальности», которая сопровождает все этапы вузовского обучения иностранцев.

Модули рабочей программы дисциплины коррелируют с программами спецпредметов, дидактический материал разработанного нами учебного пособия отобран, организован, прошел соответствующую экспертизу и отвечает задачам обучения и нормам, принятым в учебно-профессиональном дискурсе авиационных специалистов. Тексты и функционально связанные с ними иллюстративные материалы и задания соответствуют критериям аутентичности: имеют логическую целостность и тематическое единство, естественность лексиче-

\author{
Асейкина Лариса Степановна \\ К.п.н., доцент, Краснодарское высшее военное \\ авиационное училище летчиков \\ l.aseykina@gmail.com \\ Кашина Лариса Георгиевна \\ старший преподаватель, Краснодарское высшее военное \\ авиационное училище летчиков
}

Аннотация: В статье рассматривается проблема обеспечения доступности аутентичных материалов учебного пособия по языку специальности в обучении иностранных военнослужащих. Обоснована методология исследования, выявлены педагогические условия для достижения цели, представлены рекомендации для организации учебно-методической работы. В ходе экспериментальной проверки доказана необходимость реализации комплексных мер в достижении доступности учебных материалов, а значит, у курсантов появляется возможность формировать и наращивать коммуникативную компетенцию в учебно-профессиональной сфере.

Ключевые слова: аутентичные материалы, дифференциация, язык специальности, адаптация, доступность, иностранные военнослужащие.

ского наполнения и грамматических форм, адекватность в употреблении языковых средств [10].

В процессе апробации учебного пособия, изучения проблем обучения ИВС первого курса (опрос, анализ объективных показателей) выявлены основные причины трудностей в освоении материала пособия: слабое владение русским языком (40\% опрошенных), сложность учебно-методических материалов (35\% респондентов), непривычная организация учебного процесса, в том числе и самостоятельной работы (20\% опрошенных). Проблемы в обучении, в основном, вызваны значительными различиями стартовых позиций: поздним заездом для довузовской подготовки, состоянием здоровья, сложной адаптацией, социокультурными и психологическими особенностями иностранцев (мотивация, менталитет, уровень образования, знание иностранных языков и др.). В связи с разными причинами аутентичный материал учебного пособия по языку специальности (предложенный объем, лексико-грамматическое и смысловое наполнение текстов в пределах обозначенного в темпланах лимита времени) становится малодоступным, что снижает мотивацию ИВС к обучению, создает барьеры в изучении общеобразовательных и профильных 
дисциплин. В таком случае обеспечение доступности учебных материалов является важной педагогической задачей, актуализирующей наше исследование.

В научно-методической литературе рассматриваются пути реализации принципа доступности в обучении ИВС «В целях более эффективной организации образовательного процесса» $[12$, с. 3] и повышения качества профессиональной подготовки курсантов [7]. Предлагается дифференциация обучения «как направления гуманизации образовательного процесса в военном вузе», «позитивный фактор профессионального становления офицеров-специалистов» [2, с. 9]. Отмечается основное требование принципа доступности: приведение «содержания, методов и форм обучения в соответствие с возрастными, социокультурными, психологическими, национальными, религиозными и иными особенностями, а также уровнем развития обучающихся» $[12$, с. 20]. К работе с отдельными группами курсантов методисты советуют подходить дифференцированно и создавать оптимальные условия для их успешного обучения $[2,7,8]$.

Одним из способов решения проблемы доступности предлагается «оперативное изменение дидактических материалов с учетом специфики характеристик обучающихся» $[12$, с. 2], в частности, методическая обработка (адаптация) аутентичных учебных материалов в соответствии с критериями методической аутентичности [8, 10]. Тем не менее, в литературе по указанной проблеме отсутствуют системные исследования, позволяющие теоретически и практически обозначить аспекты педагогической деятельности по обеспечению доступности учебных материалов по языку специальности для обучения ИВС, что и обусловило направление нашего исследования.

Целью статьи является определение методологии исследования, выявление комплекса условий, обеспечивающих доступность учебных материалов по языку специальности для некоторых групп иностранных военнослужащих.

Задачи исследования - представить совокупность принципов и подходов, которые определяют теоретическую основу исследования; рассмотреть педагогические условия для достижения доступности материалов учебного пособия и практические рекомендации с целью организации учебно-методической работы.

Научная новизна исследования состоит в обосновании методологической основы обеспечения доступности учебных материалов для некоторых групп обучающихся, а также в определении педагогических условий, выполнение которых сделает учебные материалы понятными, а следовательно, приведет к формированию и наращиванию у курсантов учебно-профессиональной коммуникативной компетенции.

В поисках оптимального решения проблемы исследования, В стремлении теоретически и практически обосновать векторы педагогической деятельности мы опираемся на совокупность взаимосвязанных методологических подходов, среди которых дифференцированный, личностно-деятельностный, функциональнокоммуникативный подходы, которые базируются на определенной системе общедидактических принципов, включают в себя стратегию деятельности, ее методы и формы.

Дифференцированный подход к реализации задач обучения предполагает адаптацию ИВС к новым условиям жизни, службы и обучения, уровневую дифференциацию учебных программ и методик, учет индивидуальных способностей, возможностей и потребностей через вариативную организацию учебного процесса. Учитываются «особенности познавательных (содержание, объем, качество усвоения информации), деятельностных (умения и навыки), личностных (физические, нравственные, социально-психологические) качеств курсантов» $[2$, с. 3]. «Предметно-дидактическая дифференциация в обучении обеспечивает индивидуальный подход и связана с системной организацией научных знаний, учетом их содержания, объективной трудности, новизны, уровня интегрированности» [7, с. 11].

В системе принципов дифференцированного обучения есть требования «профессиональной направленности, сознательности и творческой активности, доступности и дидактической вариативности, реализации обратной связи, консультирования, мониторингового слежения» [7, с. 9]. Каждый из принципов выступает в качестве правила деятельности преподавателя и курсантов, а вместе эти требования служат для полного раскрытия индивидуальных способностей каждого курсанта, создания оптимальных условий для обучения и достижения учебно-воспитательных целей.

Личностно-деятельностный подход связан с методической обработкой (адаптацией) аутентичных учебных материалов, с помощью которых можно управлять учебной деятельностью ИВС, исходя из их особенностей и интересов. При адаптации сохраняются «основные свойства аутентичных произведений с поправкой на конкретные задачи обучения и языковой уровень учащихся», т.е. материалы сочетают «естественную коммуникацию и методическую эффективность» [10, с. 28], соответствуют критериям методической аутентичности [1, с. 15]. В рамках данного подхода реализуются общедидактические принципы: научности, доступности, наглядности, активности и сознательности, обеспечения отбора информации и др. 
Способами реализации подхода является деятельность педагогов по преобразованию имеющихся аутентичных учебных материалов «в поиске новых способов коммуникации» [1, с. 13], а также учебно-познавательная и коммуникативная деятельность ИВС, направленная на повышение мотивации, активизацию и личностное развитие. Понимание учебно-профессионального материала (специальных текстов и заданий на их основе) становится главным мотивирующим фактором для формирования коммуникативной компетенции курсантов, развития всех видов речевой деятельности. А использование «интерактивных методов обладает личностно-созидающими возможностями» [3, с. 78].

Функционально-коммуникативный подход применим к использованию адаптированных материалов в обучении языку специальности, нацеливает на выполнение задач изучения дисциплины. Реализация подхода осуществляется посредством речевой деятельности, организуемой системой пред-, при- и послетекстовых заданий и упражнений с учетом индивидуальных особенностей ИВС.

С точки зрения методики данный подход - это «действительно работающая эффективная технология» [9, с. 237], которая основывается на функциональной грамматике, идущей от «функции к средствам», т.е. от смысла, значения слов к использованию языковых средств в коммуникации $[13$, с. 25]. При обучении языку специальности в центре внимания оказывается отбор и организация языковых средств (в первую очередь, активных пластов терминологической системы) и особенности их функционирования в авиационно-техническом дискурсе для передачи смысла высказываний.

Рассмотренные методологические подходы обозначают с разных сторон пути решения исследуемой проблемы, их анализ позволяет предположить, что для достижения доступности учебного материала необходимо реализовать следующие педагогические условия: диффреренцированное обучение отдельных групп ИВС; методическая обработка (адаптация) материала учебного пособия по языку специальности; использование для обучения специальных технологий; внутрипредметная преемственность и межкафедральная учебнометодическая координация. Опыт создания и адаптации учебных пособий по языку специальности, апробация их материалов позволяют сделать определенные выводы и в целях организации педагогической деятельности по обеспечению доступности учебного материала сформулировать следующие рекомендации.

Диффреренциачия обучения иностранцев предваряется изучением социокультурных, ментальных и индивидуально-психологических особенностей курсантов, уровня их образования и языковой подготовки. Обуче- ние ведется в подгруппах в соответствии со специализацией и уровнем коммуникативной компетентности курсантов. Вариативность дает возможность предъявлять учебный материал разного уровня сложности, а для работы с ним выбирать соответствующие методы. Следует создавать благоприятную атмосферу, способствующую пониманию ИВС задач обучения и росту мотивации.

Выбор способов методической обработки учебных материалов и технологий обучения связан с выделением наиболее сложных для изучения языковых явлений, определением «меры трудности усвоения содержания военно-образовательного процесса» $[12$, с. 6]. При адаптации специального текста используется комбинация нелингвистических приемов (цитация, исключение, перестановка), связанных с изменениями композиции и структуры текста, и лингвистических (замена, редукция, добавление, инверсия), затрагивающих сферу языка. В тексте исключаются детали, избыточная информация, сокращаются и упрощаются предложения, изменяется, если нужно, структура текста. Воссоздается необходимая для понимания референтной ситуации система знаний - вторичный текст, содержательно-когнитивно связанный с текстом-источником и сохраняющий его информационное ядро и понятийный аппарат [1, с. 13]. «Принцип научности и необходимой достаточности соблюдается в квалификации и характеристике изучаемых языковых явлений» [6, с. 97], в представлении терминологии, в использовании частотных языковых моделей, свойственных подъязыку специальности.

В рецептивных и репродуктивных заданиях и упражнениях сохраняются элементы профессионального дискурса, основное назначение и функциональная аутентичность. Максимальное использование изображений (рисунков, фотографий, схем, таблиц) облегчает и ускоряет понимание предметной лексики, восприятие классификации объектов и явлений. Учебный материал должен быть построен с учетом фоновых знаний и запросов» [11, с. 59] обучающихся, опираться на их языковое сознание, языковую картину мира и быть понятным.

Использование адаптированного учебного материала требует поиска специальных педагогических технологий, адекватных запросу, для целесообразной организации аудиторной и самостоятельной работы ИВС. Эффективной технологией является коммуникативный подход, преимущество которого - отсутствие строгих рамок для ведения урока, возможность разработки различных вариантов, комбинаций заданий и структуры содержания занятия [4]. Функциональная методика позволяет акцентировать внимание на освоении лексического материала и конструкций научно-профессиональной речи.

На начальном этапе обучения многие курсанты 
нуждаются в педагогическом сопровождении: консультировании, поддержке, помощи в освоении учебных материалов. Актуальны модели выполнения заданий, вспомогательный материал для построения высказываний, варианты для выбора языковых средств, опора на родной язык курсантов (предварительный перевод новых слов), минимизация перефразирования и уменьшение объема заданий. Задачей преподавателя становится помощь курсантам в преодолении психологических барьеров и пассивности, обусловленных малодоступностью учебного материала, а также постепенное введение интерактивных методов и приемов обучения, стимулирующих самоактуализацию курсантов и развитие коммуникативности.

Внутрипредметная преемственность и межкафедральная учебно-методическая координация требуется при обучении иностранцев русскому языку сначала на подготовительном курсе (общее владение с элементами научно-профессионального модуля), а затем на основных курсах (язык специальности). На подготовительном и основных курсах преемственность выстраивается с учетом интересов и особенностей ИВС (этнопсихологических, общеобразовательных, индивидуальных), времени обучения и достигнутого уровня языковой подготовки. Отбирается и распределяется лексико-грамматический материал, организуется дифференцированное обучение, готовятся варианты учебных материалов разного уровня сложности, применяются специальные технологии обучения.

На уровне межкафедрального согласования, исходя из профессиональных потребностей и реальных коммуникативных возможностей иностранцев, происходит отбор и экспертиза текстов, координация их структуры и содержания, организация методического сопровождения учебного процесса. Ведется мониторинг учебной деятельности ИВС, и выявляются проблемные зоны, вырабатываются единые требования (к учебным текстам, использованию терминологии, адаптации учебных ма- териалов, аттестации курсантов и т.д.) с учетом дифференциации обучения. Важно обеспечивать выполнение программных требований, сохранение базового уровня знаний и умений для последующего наращивания коммуникативной компетенции и постепенно усложнять, расширять и разнообразить учебно-дидактический материал.

Проведенная методическая обработка аутентичных материалов учебного пособия по языку специальности в соответствии с параметрами методической аутентичности, а затем и экспериментальная проверка с использованием «критериев уровня владения ИВС русским языком в рамках профессионально-ориентированного обучения» [5, с. 255] показали их эффективность. Доказаны востребованность в понятных адаптированных материалов для курсантов, усиление их мотивации к обучению, наращивание познавательной и творческой активности в поиске профессиональной информации, чтении дополнительной литературы, в беседах со специалистами [1, с. 16].

В процессе эксперимента также стало очевидно, что позитивный результат в обучении достигнут только благодаря комплексным мерам в решении проблемы доступности. Необходимо реальное выполнение взаимосвязанных педагогических условий, которые обеспечивают курсантам возможность формировать и наращивать коммуникативную компетенцию в чтении и понимании специальных текстов, в умениях и навыках вести учебно-профессиональный диалог.

Осмысление методологии педагогического проектирования, разработка конкретных мер и рекомендаций для его реализации, представленные в исследовании, могут быть полезны для использования в педагогической практике. Творческий подход преподавателей к преобразованию учебных материалов, учет профессиональных интересов и потребностей ИВС, уровня их языковой подготовки, условий работы с каждой конкретной группой способствуют решению проблемы доступности.

\section{ЛИТЕРАТУРА}

1. Асейкина Л.С., Кашина Л.Г. Методическая обработка аутентичных учебных материалов по языку специальности для иностранных военнослужащих // Современная наука: актуальные проблемы теории и практики. Серия: Гуманитарные науки. - 2021. - № 05/3. - С. 11-16.

2. Белошицкий А.В. Дифференцированное обучение курсантов военного вуза как фактор профессионального становления военных специалистов. Автореферат дисс. ... канд. пед. наук: 13.00.01, 13.00.08. - Воронеж, 2004. 24 с.

3. Гладков А.В, Прохорова М.П., Ваганова 0.И. Личностно-деятельностный подход к профессиональному образованию // Проблемы современного педагогического образования, 2018, № 58-3. С. 77-80.

4. Занкова А.А. К практике использования коммуникативного подхода в преподавании русского языка как иностранного //Международный информационно-аналитический журнал «Crede Experto: транспорт, общество, образование, язык». Выпуск № 4(11). 2016. - C. 141-150. (http://ce.if-mstuca.ru).

5. К Казачкова М.Б. Профессиональный язык как отражение профессиональной культуры: Монография. М: «0ргсервис - 2000», 0динцово, 2010. 112с.

6. Кондрашова 0.В., Шельдешова И.В. Сочетание текстовых упражнений в учебных пособиях по иностранному (русскому) языку для курсантов авиацион- 
ных специальностей. // Актуальные проблемы теоретической и прикладной лингвистики. Материалы VI Всероссийской научно-практической конференции. 16-17 июля 2020 года. - Краснодар: Краснодарское ВВАУЛ, 2020. С. 91-102.

7. Логинова Л.А. Комплексное дифференцированное обучение как средство повышения качества профессиональной подготовки курсантов военно-инженерных вузов (на примере преподавания математики). Автореферат дисс. ... канд. пед. наук: 13.00.08 - Челябинск, 2008. 26 с.

8. Мирошникова Е.А. Адаптация текстового учебного материала при дифференцированном обучении иностранному языку. // Вестник Брянского госуниверситета, 2016(3). С. 229-234.

9. Нестерова Е.Н., Федорова Е.А. Русский язык как иностранный: функционально-коммуникативная модель профессионально ориентированного обучения. // Актуальные проблемы гуманитарных и естественных наук. 2012. - № 02 (37). - М. - С. 236-241.

10. Носонович Е.В., Мильруд Р.П. Параметры аутентичного учебного текста // Иностранные языки в школе. - 1999. - № 1.- С. $18-23$.

11. Первухина С.В. Структура, семантика и прагматика адаптированного текста: диссертация ... доктора филолог. наук: 10.02.19. - Ставрополь, 2016. 302 С.

12. Тенитилов П.С. Обучение иностранных военнослужащих на основе принципа доступности. Автореферат дисс. ... канд. пед. наук: 13.00.08. М., 2018. 24 с.

13. Федосов В.А. 0 коммуникативной методике преподавания РКИ // Русский язык за рубежом, № 1, 2011. С. 25 -29.

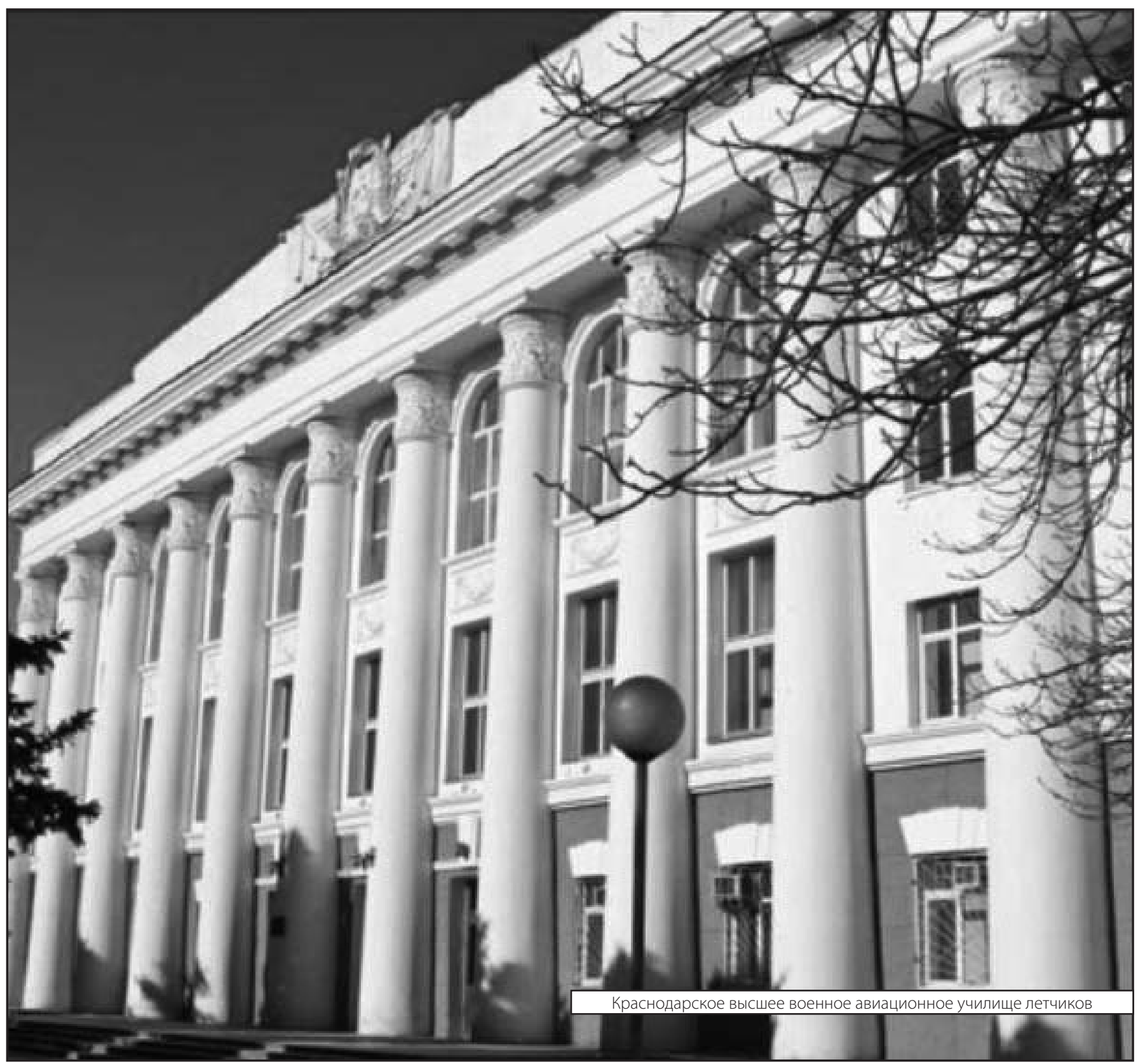

